\title{
DADOS ORGÂNICOS: UM JOGO DIDÁTICO NO ENSINO DE QUÍMICA
}

\author{
H. Y. S. Souza' e C. K. O Silva' \\ ${ }^{1}$ Secretária de Estado da Educação e da Cultura do RN, SEEC RN, Brasil \\ hialesouza@yahoo.com.br - celyna_ceu@yahoo.com.br
}

Artigo submetido em outubro/2011 e aceito em junho/2012

\section{RESUMO}

Nas últimas décadas, os jogos didáticos vêm ganhando espaço nas salas de aula, onde professores utilizam essa ferramenta com a meta de complementar seus recursos educativos e tornar a aula mais dinâmica e interativa, não apenas como uma forma de transmissão de conhecimento, mas também como compartilhamento deste. Portanto, este artigo tem como objetivos propor um jogo didático para o Ensino de Química na temática nomenclatura das funções orgânicas, assim como relatar a experiência de aplicação desse subsídio nas escolas do Ensino Médio em Natal, Rio Grande do Norte. Após a aplicação do jogo durante as aulas, foram observados aspectos como motivação e interesse dos alunos em descobrir a nomenclatura dos compostos formados. Logo, tem-se que essa proposta teve seus objetivos atingidos, concluindo-se que o jogo pode ser uma excelente alternativa auxiliar/complementar no Ensino de Química.

PALAVRAS-CHAVE: jogo didático, funções orgânicas, ensino-aprendizagem.

\section{ORGANICS DICE: A DIDACTIC GAME IN THE TEACHING OF CHEMISTRY}

\section{ABSTRACT}

Nowadays, didactics games are getting space in classrooms where teachers use this tool with a goal to supplement the educational resources and make the class more dynamic and interactive, not just as a way of transmitting knowledge, but also as a share of it. Therefore, this article aims to propose an educational game for teaching chemical nomenclature in the theme of organics functions, as well as to report the experience of applying this subside in the high school in Natal city of Rio Grande do Norte state. After the game application during the class, it was observed aspects such as motivation and students interest in discovering the nomenclature of the compounds formed. So we have that this proposal has met their goals, which concludes that the game can be an excellent alternative auxiliary /supplementary in the Teaching of Chemistry.

KEY-WORDS: didactic game, organics functions, teaching-learning. 


\section{DADOS ORGÂNICOS: UM JOGO DIDÁTICO NO ENSINO DE QUÍMICA}

\section{INTRODUÇÃO}

O ensino de Ciências no Brasil tem enfrentado dificuldades no que se refere ao desenvolvimento da prática pedagógica dos professores dessa área e isso decorre do pouco tempo em que o Ensino de Ciências foi incorporado no sistema educacional brasileiro. (PIMENTA, 1999). Segundo Freire (2001), ensinar não é transferir conhecimentos, mas criar possibilidades para sua produção ou sua construção. A educação deve favorecer a aptidão natural da mente em formular e resolver problemas essenciais e, de modo correlato, estimular o uso total da inteligência geral. (MORIN, 2003).

A compreensão dos conteúdos da Química está relacionada com uma nova visão da ciência e do conhecimento científico que não se configura num corpo de teorias e procedimentos de caráter positivista, e sim, como modelos teóricos social e historicamente produzidos. (ZAZON et al., 2008). É difícil, em uma escola, encontrarmos alunos que apresentem afinidade com os conteúdos da disciplina Química. Esse fato pode ser atribuído aos métodos tradicionais de ensino que, aliados aos conteúdos complexos, tornam as aulas monótonas e desestimulantes.

A prática, do ensino de Química Orgânica no Ensino Médio, em sala de aula, consiste na transmissão-recepção de conhecimentos que, muitas vezes, não são compreendidos. Para estimular e resgatar o interesse dos discentes pelas aulas de química é fundamental que o professor busque metodologias diferenciadas que o auxiliem no processo de ensino aprendizagem. (SOARES et al., 2003). O desenvolvimento de estratégias modernas e simples, utilizando experimentos, jogos e outros recursos didáticos, é recomendado para dinamizar o processo de aprendizagem em Química. (SOARES et al., 2003).

Os jogos proporcionam ao aluno uma forma prazerosa e divertida de estudar, além de oferecer ao professor uma maneira diferente de avaliar a assimilação do alunado em relação aos conteúdos estudados, de revisar conteúdos ou como um meio mais dinâmico de fixar o conhecimento, permitindo a identificação de erros de aprendizagem. (ZANON et al., 2008). Além disso, o professor pode auxiliar o aluno na tarefa de formulação e reformulação de conceitos, ativando seus conhecimentos prévios e articulando-os a uma nova informação que está sendo apresentada. (POZO, 1998).

A principal vantagem do uso de jogos didáticos envolve a motivação, gerada pelo desafio, acarretando o desenvolvimento de estratégias de resolução de problemas, a avaliação das decisões tomadas e a familiarização com termos e conceitos apresentados. Os jogos pedagógicos aliam o aprendizado de determinados conteúdos à atividade lúdica, despertando interesse dos alunos no assunto abordado e propiciando uma aprendizagem eficaz, divertida e empolgante. Por esse motivo, o jogo se torna uma peça de importância quando se quer atrair a atenção do aluno para determinado conteúdo em que ele oferece resistência. No momento em que ele encara o jogo como uma brincadeira, aprende o conteúdo sem perceber. (KISHIMOTO, 1994). No entanto, o jogo não deve ser utilizado ao acaso, mas visto como uma das atividades dentro de uma sequência definida de aprendizagens e um meio a ser usado para se alcançar determinados objetivos educacionais.

Vários autores têm enfatizado a eficiência do jogo didático, no Ensino de Química, em despertar a atenção dos alunos, a qual é baseada no aspecto lúdico, que, geralmente, produz 
efeito positivo no aspecto disciplinar. (SOARES \& CAVALHEIRO, (2006); OLIVEIRA \& SOARES, (2005); EICHLER \& DEL PINO, (2000); GIORDAN, (1999); RUSSELL, (1999); SANTOS \& MICHEL, (2009)). Diversos temas em Química podem ser explorados com o auxílio de jogos didáticos. Por acreditar em sua eficácia como ferramenta de apoio ao ensino, foi desenvolvido, no decorrer desta pesquisa, um jogo para o Ensino de Química. Jogos desse tipo podem contemplar alguns dos conteúdos em sala de aula com o objetivo de facilitar o entendimento e de romper com a ideia de que as aulas de Química são chatas e monótonas.

Ao se perceber as dificuldades que permeiam o trabalho do professor nesse nível de ensino, optou-se por estudar uma forma de contribuir para o processo de ensino-aprendizagem no ensino de nomenclatura dos compostos orgânicos, na medida em que o tema funções orgânicas é de entendimento complexo, pois os alunos não apresentam a habilidade de associar facilmente a estrutura ao nome correspondente à função. Um jogo didático pode abordar o tema de forma a facilitar essa associação, permitindo ao aluno uma melhor compreensão do conteúdo. Portanto, o jogo Dados Orgânicos tem como objetivo auxiliar os alunos do Ensino Médio a explorarem as relações existentes entre a estrutura das funções orgânicas e a nomenclatura dos compostos, utilizando-se de vários tipos de dados referentes ao tipo de função, ao número de carbonos, ao tipo de ligaçãoe às posições das funções e insaturações.

Mesmo que o aluno não tenha um desempenho satisfatório durante a aplicação do jogo, é preciso considerar o que aprende durante a atividade, pois, como o jogo não tem o peso de uma avaliação formal, ele se sente à vontade para arriscar as respostas, o que pode vir a confirmar sua suspeita ou a esclarecer alguma dúvida apresentada em relação ao conteúdo abordado.

\section{PROPOSTA PEDAGÓGICA}

O jogo relaciona a estrutura das funções orgânicas com a nomenclatura dos compostos, utilizando vários tipos de dados referentes ao tipo de função, ao número de carbonos e ao tipo de ligação. Assim, com a utilização dos dados, é possível nomear cada composto formado, adotando a nomenclatura oficial IUPAC (International Union of Pure and Applied Chemistry) para compostos orgânicos. A carta informativa complementar também conterá a nomenclatura usual, caso seja necessário, do respectivo composto.

\section{MATERIAIS}

O jogo totaliza cinco dados de seis faces. Primeiramente, foram construídos cinco cubos de isopor utilizados como preenchimento do dado para evitar qualquer deformação. Os cubos foram cobertos com cartolinas recortadas com base no molde representado pela Figura 1 e recobertos com adesivo transparente para proteção. 


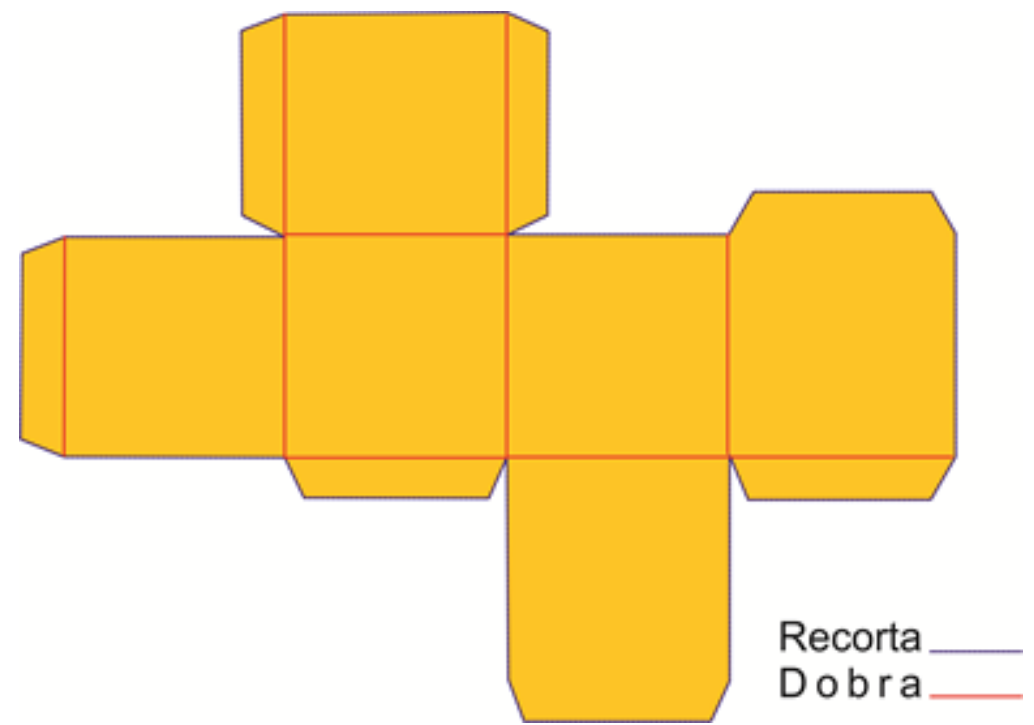

Figura 1: Molde para primeira cobertura do cubo.

Antes da colagem do adesivo transparente nos dados, imagens das estruturas das funções, do número de carbono, do tipo de ligação, da posição do grupo funcional e da posição da insaturação foram impressas em folhas $A 4$ e fixadas sobre as faces dos dados. $O$ dado 1 (Figura 2) refere-se ao tipo de função orgânica, sendo abordadas as funções: hidrocarboneto, álcool, aldeído, cetona, ácido carboxílico e éter (Tabela 1). 0 dado 2 (Figura 3) indica o número de carbono, em que cada face determina um valor, variando de um a seis. 0 dado 3 (Figura 4) é referente à posição do grupo funcional, que varia de 1 a 3 , repetindo duas vezes cada número da posição. 0 dado 4 (Figura 5) é referente ao tipo de ligação, sendo duas faces para a ligação simples, duas faces para a ligação dupla e duas faces para a ligação tripla. Caso haja insaturação, o dado 2 será jogado novamente, mas dessa vez para indicar a posição da insaturação. Os modelos dos dados estão apresentados nas Figuras 2, 3, 4 e 5.
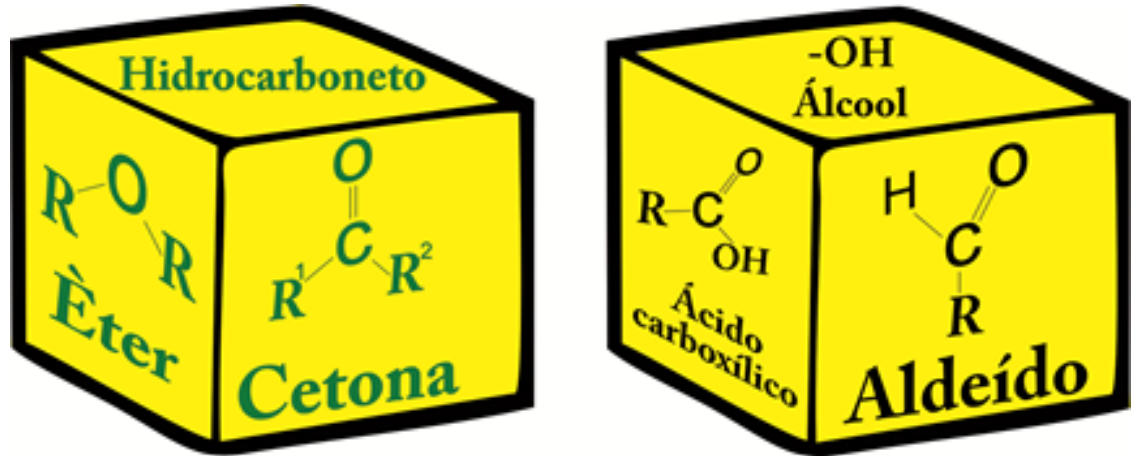

Figura 2: Modelo proposto para os dados de seis faces do jogo Dados Orgânicos, referentes a seis grupos funcionais pertencentes às funcões orgânicas (dado 1). 


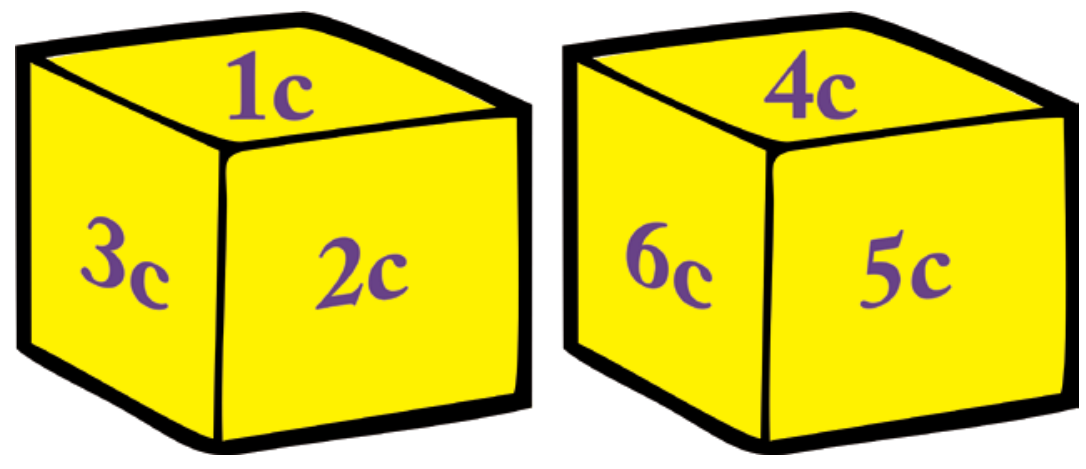

Figura 3: Modelo proposto para o dado de seis faces do jogo Dados Orgânicos, referente ao número de carbonos (dado 2).

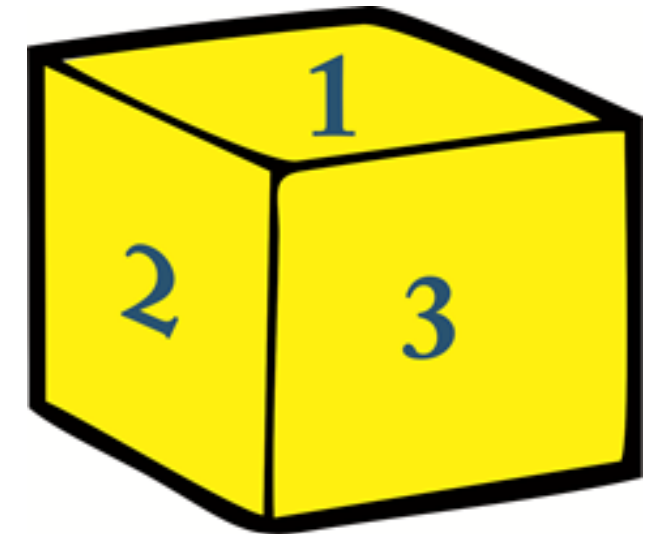

Figura 4: Modelo proposto para o dado de seis faces do jogo Dados Orgânicos, referente à posição do grupo funcional (dado 3).

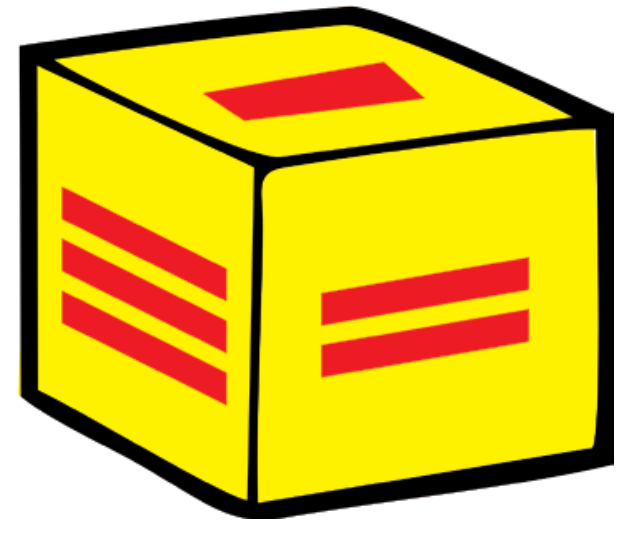

Figura 5: Modelo proposto para o dado de seis faces do jogo Dados Orgânicos, referente aos tipos de ligação: simples(-), dupla(=) e tripla( इ) (dado 4).

O jogo foi, ainda, complementado com cartas informativas sobre cada composto. As cartas contêm algumas informações como: fórmula molecular e estrutural, massa molar, propriedades físicas e químicas e aplicações. No verso das cartas, foi escrito o nome do jogo 
(Dados Orgânicos). Para sua construção, imprimiram-se as cartas em folha A4, as quais, posteriormente, foram recortadas, coladas em cartolinas e recobertas com adesivo transparente para proteção. 0 modelo das cartas para a molécula do metano é apresentado na Figura 6 .

\section{METANO}

Fórmula molecular: $\mathrm{CH}_{4}$ Fórmula estrutural:

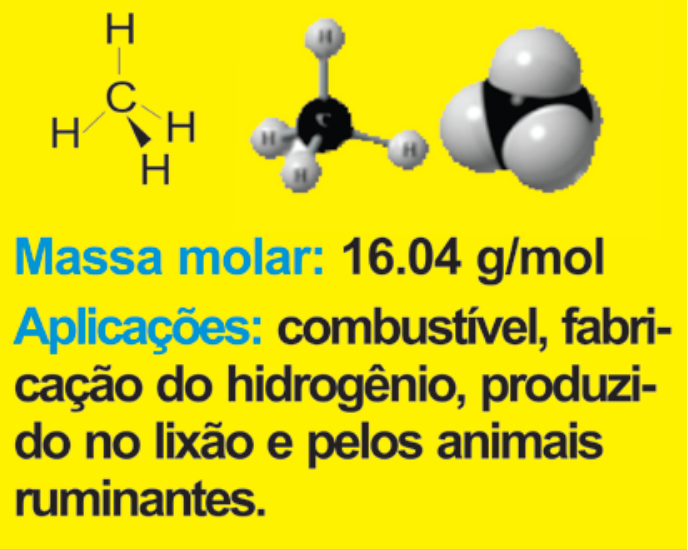

Figura 6: Modelo de carta informativa complementar proposta para o jogo Dados Orgânicos.

\section{ANTES DE JOGAR}

Após o aluno reconhecer as funções orgânicas e as regras de nomenclatura durante as aulas expositivas, a aplicação do jogo Dados Orgânicos é significante para o discente se familiarizar com os grupos funcionais, relacionando-os com o conteúdo visto anteriormente. Dessa maneira, os alunos podem saber o nome de cada composto através das informações fornecidas por cada um dos dados e das tabelas, bem como suas aplicações e propriedades por meio das cartas informativas. O professor pode fazer comentários adicionais tanto relacionados as substâncias encontradas quanto relacionados a outras substâncias. O jogo Dados Orgânicos foi aplicado em três turmas do terceiro ano do Ensino Médio da Escola Estadual Professora Ana Júlia Mousinho e da Escola Estadual Professor Paulo Pinheiro (ambas em Natal, Rio Grande do Norte), totalizando 110 alunos, no ano de 2011.

\section{O JOGO}

Para participar do jogo Dados Orgânicos, podem ser formados dois ou mais grupos, os quais devem observar suas regras (Anexo). Um dos grupos pode iniciar o jogo lançando o conjunto de dados, respectivamente: o dado 1 (grupo funcional), na sequência, o dado 2 (número de carbonos), depois o dado 3 (posição do grupo funcional), em seguida, é jogado o dado 4 (tipo de ligação) e, por último, caso o composto em formação tenha insaturação, será jogado o dado 2 novamente, o qual, agora, indicará a posição da insaturação. Ao término do lançamento dos 
dados, cada grupo tem apenas 60 segundos para pronunciar o nome do composto e desenhar ou montar sua fórmula estrutural e molecular. Assim, se o grupo não responder, passará a vez para o outro grupo, sendo cada acerto pontuado a critério do professor. O grupo que ao término do jogo obtiver maior pontuação será o vencedor. Durante as duas primeiras jogadas, os grupos terão acesso às tabelas.

No caso de o grupo acertar o nome e as fórmulas estrutural e molecular do composto, o professor deve, ainda, assumir a função de mediador entre os grupos, comentando sobre o composto e as informações apresentadas na carta informativa complementar da molécula, esclarecendo possíveis dúvidas e também motivando a discussão e exposição de diferentes pontos de vista.

Para avaliar a contribuição do jogo na melhora do desempenho dos alunos, foram aplicados testes referentes ao conteúdo abordado (Anexo III). Assim, pode-se verificar a eficiência da utilização de jogos didáticos como ferramenta no processo da aprendizagem. Os testes foram entregues antes e após a aplicação do jogo Dados Orgânicos com dez questões objetivas sobre o assunto de funções orgânicas. Aplicou-se o pré-teste com o objetivo de avaliar o conhecimento adquirido apenas com a aula de nomenclatura de funções orgânicas. O pós-teste, composto pelas mesmas questões, consistiu em verificar a evolução dos alunos após a aplicação do recurso didático. Para quantificação do rendimento dos alunos antes e depois do jogo, foi relacionado o conceito de rendimento com a porcentagem de acertos como apresentada na Tabela 01:

Tabela 01: Conceitos de acordo com a porcentagem de acertos.

\begin{tabular}{|c|c|}
\hline CONCEITOS & \% DE ACERTOS \\
\hline Ruim & $<50$ \\
\hline Regular & $50-70$ \\
\hline Bom & $70-80$ \\
\hline Ótimo & $>80$ \\
\hline
\end{tabular}

\section{DISCUSSÕES}

Logo no início do jogo, mesmo com o uso das tabelas, a maioria dos alunos apresentou dificuldade em montar o nome e a estrutura da molécula no tempo determinado, mas à medida que o jogo evoluía foram assimilando as informações dentro do tempo estipulado. Com base nos resultados dos testes corrigidos, antes e depois da aplicação do recurso, a partir das Figuras 07 (rendimento dos alunos pré-recurso) e 08 (rendimento dos alunos pós-recurso), observou-se que os alunos melhoraram significativamente seu rendimento referente ao tema abordado. Os resultados dos pré-testes mostram que antes da aplicação do recurso didático $66 \%$ dos alunos obtiveram rendimento entre regular e ruim, e $34 \%$ dos alunos obtiveram rendimento entre bom e ótimo. A análise realizada dos pós-testes mostrou que apesar da aplicação do recurso didático, ainda $25 \%$ dos alunos ficaram entre o conceito regular e ruim, esse percentual pode ser atribuído ao grupo de alunos que faltaram ou na aula teórica ou na aula da aplicação do jogo didático ou não compreenderam bem o conteúdo abordado ou as regras do jogo, sendo, portanto, constatado a relevância das duas metodologias para a melhoria do rendimento dos alunos. Dessa 
forma o jogo Dado Orgânico, pode ser considerado como uma ferramenta complementar no processo de ensino-aprendizagem.

Durante e após a realização do jogo, percebeu-se por meio dos testes aplicados, do comportamento e das opiniões dos alunos, que eles se interessaram pelo jogo, através do qual se familiarizaram com o tema mais facilmente, de uma forma prazerosa e estimulante, na medida em que podiam interagir com os diferentes grupos e com o professor como mediador.

O jogo Dados Orgânicos teve seu objetivo concretizado, visto que sua função educativa foi observada durante a aplicação, agregando-se ao jogo o aspecto lúdico, com o objetivo de desenvolver estratégias importantes para o processo de ensino-aprendizagem de Química, facilitando, assim, a compreensão de conceitos complexos e abstratos e estimulando a motivação, o raciocínio e a interação entre alunos e professor.

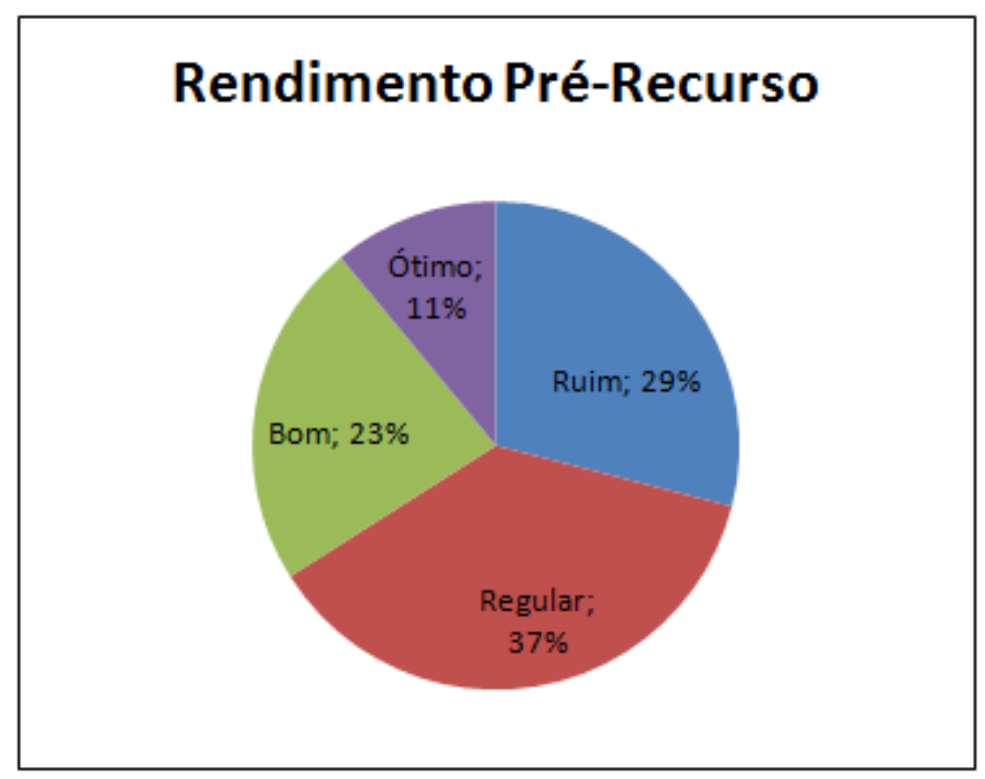

Figura 07: Rendimento dos alunos no pré-teste (teste pré-recurso).

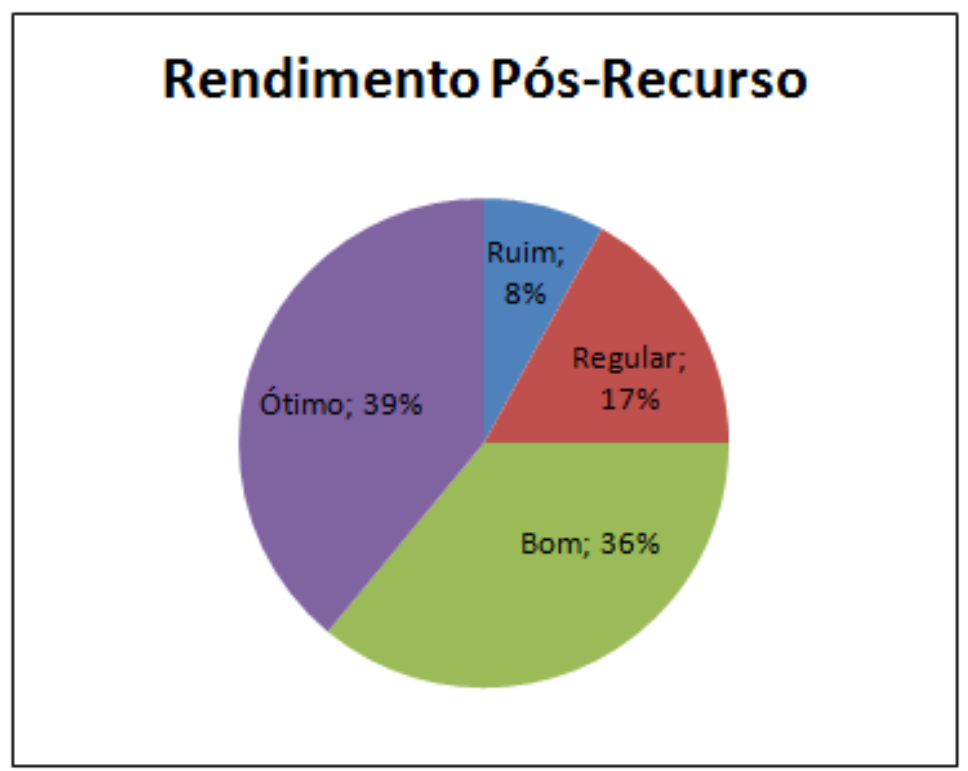

Figura 08: Rendimento dos alunos no pós-teste (teste pós-recurso). 


\section{CONCLUSÃO}

Conclui-se, portanto, que o jogo didático é uma ferramenta auxiliar e complementar para o processo de ensino-aprendizagem no Ensino de Química que contribui para que o aluno de Ensino Médio reconheça a nomenclatura dos compostos orgânicos mais simples através de uma didática interessante e divertida. A partir dessas perspectivas, tem-se que o jogo Dados Orgânicos pode ser utilizado como uma das ferramentas para subsidiar o ensino de nomenclatura em química orgânica, já que se atingiu o principal objetivo dessa proposta, ou seja, foram obtidos resultados satisfatórios em relação ao aprendizado dos alunos após a aplicação desse auxílio pedagógico.

Considera-se de suma importância esclarecer que os jogos didáticos não substituem os outros métodos de ensino, mas se apresentam como uma ferramenta auxiliar/complementar no processo de ensino-aprendizagem, dando suporte ao professor e motivação ao aluno. Os professores necessitam atentar para os objetivos da aplicação do jogo didático em sala de aula e encaminhar o trabalho adequadamente após o seu uso, além de avaliar seus efeitos no processo de aprendizagem dos alunos, tudo isso a fim de reduzir e/ou eliminar as possíveis desvantagens. Portanto, o educador deve ter a capacidade de conhecer e identificar as vantagens e desvantagens na proposta do jogo na sua prática.

Esse jogo pode se tornar ainda mais complexo e completo, quando se aumenta o número de carbonos e se inserem ramificações, por exemplo, porém é preciso observar que as regras referentes ao processo irão aumentar e, como consequência, o grau de dificuldade para os alunos se elevará, sendo de grande relevância compreender essa complexidade desde que o discente já domine o conteúdo abordado.

\section{REFERÊNCIAS}

1. EICHLER, M.; DEL PINO, J. C. Carbópolis: um software para educação química. Química Nova na Escola. n. 11, 2000, p. 10-12. Disponível em: <http://qnesc.sbq.org.br/online/qnesc11/v11a02.pdf>. Acesso em: 06 ago. 2011.

2. FREIRE, Ana Maria Araújo. A pedagogia da libertação em Paulo Freire. São Paulo: Unesp, 2001, 330p.

3. GIORDAN, M. O papel da experimentação no ensino de ciências. Química Nova na Escola. $\mathrm{n}$. 10, p. 43-49, 1999.

4. KISHIMOTO, T. M. Jogo, Brinquedo, Brincadeira e a Educação. São Paulo: Cortez, 1996. 183p.

5. . O jogo e a educação infantil. São Paulo: Pioneira, 1994.

6. MELO, C. M. R. As atividades lúdicas são fundamentais para subsidiar o processo de construção do conhecimento (continuação). Información Filosófica, v. 2, n. 1, p. 128-137, 2005.

7. MIRANDA, S. No Fascínio do jogo, a alegria de aprender. Ciência Hoje, v. 28, p. 64-66, 2001.

8. MORIN, E. A cabeça bem-feita: repensar a reforma, reformar o pensamento. 8a ed. Rio de Janeiro: Bertrand Brasil, 2003. 128p. 
9. OLIVEIRA, A. S.; SOARES, M. H. F. B. Júri químico: uma atividade lúdica para discutir conceitos de química. Química Nova na Escola, n. 21, p. 18-24, 2005.

10. PIMENTA, Selma G. (Ed). Saberes pedagógicos e atividade docente. 2ª ed. São Paulo: Cortez, 1999. 248p.

11. POZO, J. I. Teorias Cognitivas da Aprendizagem. 3ạ ed. Tradução de J. A. Llorens. Porto Alegre: Artmed, 1998. 284p.

12. RUSSELL, J. V. Using games to teach chemistry: An Annotated Bibliography. Journal of Chemical Education, 1999, 76 (4), p 481.DOI: 10.1021/ed076p481. Publication Date (Web): April 1, 1999.

13. SANTOS, A. P. B.; MICHEL, R. C. Vamos jogar uma SueQuímica? Química Nova na Escola. n. 31, p. 179-183, 2009.

14. SOARES, M. H. F. B.; CAVALHEIRO, E. T. G. O ludo como um jogo para discutir conceitos em termoquímica. Química Nova na Escola, n. 23, p. 27-31, 2006.

15. SOARES, M. H. F. B. O lúdico em Química: jogos e atividades aplicados ao ensino de Química. Tese (Doutorado em Química) - Universidade Federal de São Carlos, São Carlos, 2004.

16. SOARES, M. H. F. B.; OKUMURA, F.; CAVALHEIRO, T. G. Proposta de um jogo didático para ensino do conceito de equilíbrio químico. Química Nova na Escola, n. 18, p. 13-17, 2003.

17. ZANON, D. A. V.; GUERREIRO, M. A. S.; OLIVEIRA, R. C. Jogo didático Ludo Químico para o ensino de nomenclatura dos compostos orgânicos: projeto, produção, aplicação e avaliação. Ciências \& Cognição, v. 13, n. 1, p. 72-81, 2008. 


\section{ANEXO I}

\section{Regras Gerais}

- Caso o dado 2, indicando a posição da insaturação, indicar insaturação maior do que o número de carbonos, essa deve ser nomeada como insaturação no último carbono possível.

\section{Regras Específicas}

\section{Hidrocarboneto}

- Se o dado 1 indicar a função hidrocarboneto, o dado 2 indicar dois ou três carbonos e caso o dado 3 indique insaturação, não é necessário lançar o dado que mostra a posição da insaturação.

\section{Álcool}

- Se o dado 1 indicar a função álcool e o dado 2 indicar dois carbonos não é necessário jogar o dado que mostra a posição da função.

\section{Cetona}

- Se o dado 1 indicar a função cetona e o dado 2 (número de carbonos) indicar 1 ou 2 carbonos, deve ser considerado a menor quantidade possível para essa função, ou seja, 3 carbonos, não sendo mais necessário jogar os outros dados.

- Para essa função, caso o dado da posição da função indicar primeiro carbono, deve ser considerada a posição da função no segundo carbono.

\section{Aldeído}

- Se dado 1 indicar a função aldeído, não é necessário jogar o dado 3 (posição do grupo funcional).

- Se o dado 1 indicar a função aldeído e o dado 3 (tipo de ligação) indicar insaturação, deve ser considerada a menor posição a partir da posição no carbono 2.

- Para essa função, se o dado 2 (número de carbonos) indicar 1 ou 2 carbonos, não é necessário jogar os outros dados.

Éter

- Se o dado 2 indicar a função éter, é necessário jogar o dado dos números de carbonos 2 vezes e não é necessário jogar o dado posição do grupo funcional. 


\section{ANEXO II}

O Quadro 1 fornece as regras para a nomenclatura dos compostos orgânicos que acompanha o jogo Dados Orgânicos.

Quadro 1-Regras para nomenclatura dos compostos orgânicos FORMAÇÃO DO NOME DO COMPOSTO

\begin{tabular}{ccc}
\hline $\begin{array}{c}\text { No de carbonos } \\
\text { (Prefixo) }\end{array}$ & $\begin{array}{c}\text { Tipo de ligação (Infixo) } \\
1 \text { carbono(met) }\end{array}$ & Função-terminação (Sufixo) \\
\hline $\mathbf{2}$ carbono(et) & Simples(an) & Aidrocarboneto (o) \\
$\mathbf{3}$ carbono(prop) & Dupla(en) & Aldeído (al) \\
4 carbono(but) & Tripla(in) & Cetona (ona) \\
5 carbono(pent) & & Ácido carboxílico (oico) \\
6 carbono(hex) & Éter (prefixo menor \\
\hline *Na função éter, o prefixo se dá pela parte mais simples (geralmente a menor).
\end{tabular}




\section{ANEXO III}

\section{Pré-teste e Pós-teste}

\section{Assunto: Hidrocarboneto, éter, cetona, álcool, aldeído e ácido carboxílico}

1. A utilização do gás natural como combustível é uma das alternativas para as soluções que têm sido propostas para diminuição da poluição. Grande parte do gás natural (70\%) é formado por metano, esse gás pode ser obtido por fermentação anaeróbia (sem ar) de material orgânico encontrado no lixo. A estrutura molecular do metano é dada por:

a)<smiles>CCC</smiles>

c)<smiles>CCOCC</smiles>

b)<smiles>C</smiles>

d)<smiles>CC</smiles>

2. A fórmula estrutural para um alceno é representada a seguir. Esse alceno tem como nomenclatura:

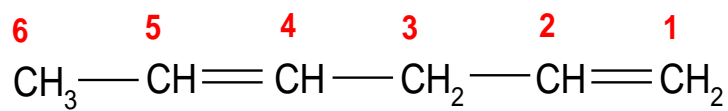
a)Hept-2-eno
b) Hex-2-eno
c) Hexa-1,4-dieno
d) Hexa-2,5-dieno

3. O Brasil é o país mais avançado, do ponto de vista tecnológico, na produção e no uso de álcool etílico como combustível, sua fórmula estrutural é apresentada a seguir. A nomenclatura oficial desse álcool é dada por:<smiles>CCO</smiles>
a) Etano
b) Etanol
c) Propanona
d) Propanol

4. A concentração de colesterol no sangue deve ser controlada, pois previne doenças cardiovasculares, apesar de desempenhar funções importantes nos processos biológicos. No 
Brasil a concentração deve ficar abaixo de 200 miligramas por 100 mililitros de sangue. 0 colesterol pertence à função:

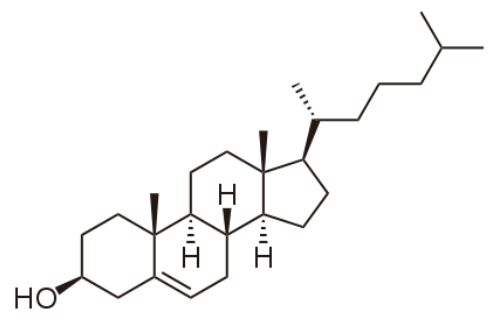
a)álcool
b) aldeído
c) cetona
d) fenol

5. As cetonas tem como principal aplicação serem utilizadas como solvente. O composto pentan2-ona, pertencente a essa função, tem como fórmula estrutural:

a)<smiles>CCCC(=O)CC</smiles><smiles>CCCCC(C)=O</smiles>

b)<smiles>CCCC(C)=O</smiles>

d)<smiles>CC(=O)CC(C)=O</smiles>

6. A vitamina $\mathrm{K}$ é encontrada na couve-flor, espinafre e fígado e é uma substância essencial para os processos de coagulação sangüínea. De acordo com a sua estrutura, abaixo esquematizada. 0 grupo funcional presente é:

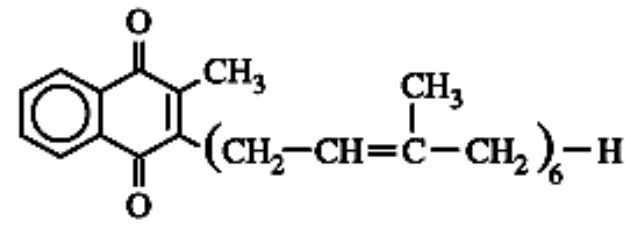
a) álcool
b) aldeído
c)cetona
d)éter

7. A estrutura a seguir, e uma substância líquida volátil e altamente inflamável. Utilizado inicialmente como anestésico, foi abandonado pelo risco de explosão e dependência, tem como grupo funcional e nomenclatura:

$$
\mathrm{CH}_{3}-\mathrm{CH}_{2}-\mathrm{O}-\mathrm{CH}_{2}-\mathrm{CH}_{3}
$$



a) hidrocarboneto, metoxietano
b) éter, etoxietano
c) hidrocarboneto, etoxietano
d) cetona, metoxietano

8. O butanal, matéria-prima para a produção de aromas sintéticos, tem como fórmula estrutural:
a)
b)
c)
d)<smiles>CCCC=O</smiles><smiles>CCCC</smiles><smiles>CCC(C)=O</smiles><smiles>CC(=O)CC(C)=O</smiles>

9. A estrutura a seguir, representa um feromônio, substância sexo-atrativa, produzida por certos insetos. Os conhecimentos sobre funções orgânicas permitem afirmar que essa substância é:<smiles>CC1(C)CCCC(C=O)C1</smiles>
a) ácido carboxílico
b) hidrocarboneto
c) aldeído
d) cetona

10. O ácido fórmico, encontrado em algumas formigas, é causador da irritação provocada pela picada desses insetos, cuja formula estrutural apresentada a seguir, tem como nomenclatura oficial:<smiles>O=CO</smiles>
a) Ácido etanóico
b) Propanona
c) Ácido metanóico
d) butanal 